\title{
Thulium: YAG Laser Vaporesection Versus Bipolar Transurethral Resection of the Prostate for the Treatment of Benign Prostatic Hyperplasia: A Comparative Study
}

\section{Mohamed Selim, Mohamed Marzouk Abdella, Mohamed Rokba, Alaa el Mahdy, Mohamed Omar}

Urology Department, Menoufia University, Shebeen El Kom, Egypt. mohammed.kamal.omar@med.menofia.edu.eg

*Corresponding Author: Mohamed Omar, MD, Lecture and Consultant of Urology, Menoufia University, Egypt. Stevan Stream Fellowship of Endourology, the Cleveland Clinic.

\section{Abstract \\ Introduction}

Benign prostatic hyperplasia (BPH) is one of the most common causes of urinary obstruction, which occurs in $50 \%$ to $60 \%$ of men $>60$ years old. Transurethral resection of the prostate (TURP) has been recognized as the gold standard surgical option for treatment of BPH. Over the past decade, different laser systems have been successfully introduced for laser prostatectomy including the Thulium laser.

Methods: From January 2016 to October 2017, we compared the safety and effectiveness of Thulium: YAG laser vaporesection (ThuVaRP) versus bipolar transurethral resection of the prostate (B-TURP) for the treatment of patients with large prostates ranged between $60 \mathrm{gm}$ and $90 \mathrm{gm}$

Results: A total of 120 patients were randomly divided into two groups and managed by ThuVaRP (58, group 1) or B-TURP (62, group 2) with mean age in ThuVaRP group $66 \pm 7$ years and $69 \pm 7$ years in B-TURP group with no significant difference. Compared to the B-TURP group, the ThuVaRP group had a less intra-operative blood loss $91 \pm 35$ vs $260 \pm 143 \mathrm{ml}(P=0.0001)$, longer operative time $117 \pm 24$ vs $101 \pm 29 \mathrm{~min}(P=0.017)$, shorter catheterization time $2.7 \pm 0.5$ vs. $3.3 \pm 0.8$ days $(P=0.001)$ and hospital stay $2.5 \pm 0.6$ vs. $3.2 \pm 0.4$ days $(P=0.0001)$ respectively.

Conclusion: ThuVaRP represents a valuable option for the management of BPH with satisfactory outcomes in terms of safety, blood loss and acceptable complications, but with longer operative time in comparison to B-TURP.

\section{STANDARD ABBREVIATIONS}

TUTP: Transurethral resection of the prostate

ThuVaRP: Thulium: YAG laser vaporesection

BMI: Body Mass Index

B-TURP: Bipolar transurethral resection of the prostate

IPSS: International Prostate Symptom Score

DRE: digital rectal examination

PVR: post-voiding residual urinary volume

Q max: maximum flow rate

PSA: Prostatic specific antigen
TUR: Transurethral resection of the prostate

\section{INTRODUCTION}

Benign prostatic hyperplasia (BPH) is one of the most common causes of lower urinary tract obstruction, that occurs in $50 \%$ to $60 \%$ of men aged 60 years or older $^{1}$. BPH can be treated with pharmacotherapy's and surgery ${ }^{2}$.Urinary retention and high post void residual are the main indicators of failed medical therapy, requiring a shift to the surgical options ${ }^{3}$. Transurethral resection of the prostate (TURP) has been recognized as the gold standard surgical option for treatment of $\mathrm{BPH}^{4}$. 
Thulium: YAG Laser Vaporesection Versus Bipolar Transurethral Resection of the Prostate for the Treatment of Benign Prostatic Hyperplasia: A Comparative Study

Over the past decade, different laser systems have been successfully utilized for laser prostatectomy ${ }^{5}$. In many studies, holmium: yttrium-aluminum-garnet (YAG) laser enucleation of the prostate (HoLEP) or Green Light laser photo selective vaporization (PVP) were proved to be safe and effective surgical procedures with a comparable long-term follow-up with regard to TURP.

The recently developed Thulium laser has been found superior to the Holmium laser in spatial beam quality and tissue incision precision and because of its ability to operate in continuous-wave pulsed modes $^{6}$. Another advantage of the Thulium laser is the vaporesection nature, which allows it to resect small pieces of prostate tissue without morcellation? ${ }^{7}$.

In our study, we assessed the safety and effectiveness of ThuVaRP versus bipolar TURP for treatment of being prostatic hyperplasia.

\section{Materials AND MethodS}

After obtaining approval by the local ethics committee of Menoufia University Hospitals, all successfully consented patients whom were indicated for the surgical treatment of BPH with prostate volume ranged between $60 \mathrm{gm}$. and $90 \mathrm{gm}$., were included in our study. Patients were randomizes through a computer-generated randomization chart to either receive, the Covidien Force Triad ${ }^{\mathrm{TM}}$ energy platform, manufactured by (Valley lab), Colorado, USA, for the bipolar group and the RevolixTM Thulium YAG 120 W, by LISA laser, Katlenburg-Lindau, Germany for the vaporesection group.
All Patients were pre-operatively evaluated through detailed medical history and physical examination (digital rectal examination) including personal data, main Complaint (urine retention, LUTS, or symptoms of complications), IPSS, history of previous surgeries and other medical problems.

Laboratory investigations including preoperative serum sodium, complete blood picture and prostatespecific antigen (PSA). Imaging evaluation including: trans-rectal and pelvi-abdominal ultrasound with estimation of post-voiding residual urine volume, prostate size and uroflowmetry (Qmax).

Intra-operative evaluation including: operative time, resected tissue volume, irrigating fluid volume, blood loss, and intra-operative complications. Postoperative evaluation included: mean hemoglobin, hematocrit and sodium level, catheterization period, hospital stay, and postoperative complications. A follow up of IPSS, Qmax, and PVR urine after 3, 6 and 12 months was also obtained for all patients.

Statistical evaluation was accomplished through Wilcoxon's signed-rank test and Fisher's exact test for univariate analysis and logistic regression for multivariate analysis, through JMP ${ }^{\mathrm{TM}}$ software.

\section{RESULTS}

A total of 120 patients; with a mean age of $68 \pm 7$ years were divided into two groups; ThuVaRP (58 patients) and B-TURP (62 patients). There were no statistically significant differences between both groups regarding preoperative parameters, (Table: 1 ).

Table 1. Comparing B-TURP and ThuVaRP group's pre-operative data evaluation

\begin{tabular}{|c|c|c|c|}
\hline Variable & B-TURP & ThuVaRP & P value \\
\hline Age & $69 \pm 7$ & $66 \pm 7$ & 0.18 \\
\hline$D M$ & $5(12.5 \%)$ & $0(0)$ & 0.6 \\
\hline HTN & $8(20 \%)$ & $2(10 \%)$ & 0.3 \\
\hline$D M+H T N$ & $6(15 \%)$ & $3(15 \%)$ & 0.9 \\
\hline IPSS & $32 \pm 3$ & $33 \pm 2$ & 0.32 \\
\hline Prostate size (gm.) & $80 \pm 9$ & $75 \pm 13$ & 0.34 \\
\hline$P V R(m L)$ & $273.4 \pm 98$ & $246.2 \pm 99$ & 0.25 \\
\hline$Q \max (\mathrm{mL} / \mathrm{sec})$ & $2.1 \pm 3.4$ & $2.4 \pm 3.9$ & 0.8 \\
\hline PSA (ng/dL) & $3.6 \pm 1.4$ & $2.9 \pm 1.2$ & 0.13 \\
\hline S.Creatinine & $1.3 \pm 0.72$ & $1.24 \pm 0.64$ & 0.46 \\
\hline$H B(g m / d L)$ & $12.9 \pm 1.3$ & $14.7 \pm 6.3$ & 0.24 \\
\hline НСТ (\%) & $38.9 \pm 4.4$ & $40.1 \pm 2.7$ & 0.25 \\
\hline $\mathrm{Na}+$ conc. $(\mathrm{mmol} / \mathrm{L})$ & $139.8 \pm 3$ & $139 \pm 2.11$ & 0.29 \\
\hline
\end{tabular}


Thulium: YAG Laser Vaporesection Versus Bipolar Transurethral Resection of the Prostate for the Treatment of Benign Prostatic Hyperplasia: A Comparative Study

A shorter operative time was noted for B-TURP significantly lesser in ThuVaRP group (Table: 2). group $101 \pm 29$ meanwhile ThuVaRP group 117 \pm 24 min with $(\mathrm{p}=0.01)$, while calculated blood loss and the resected tissue volume, were a

Postoperative hemoglobin and sodium drop were less in ThuVaRP but with no significant statistical difference (Table: 2).

Table 2. Comparing B-TURP and ThuVaRP group's operative data

\begin{tabular}{|c|c|c|c|c|c|}
\hline Variable & \multicolumn{2}{|c|}{ B-TURP } & \multicolumn{2}{|c|}{ ThuVaRP } & P value \\
\hline Immediate post-procedure HB drop (gm/dL) & \multicolumn{2}{|c|}{$0.69 \pm 0.4$} & \multicolumn{2}{|c|}{$2.2 \pm 6.3$} & 0.5 \\
\hline Immediate post-procedure Hct drop (\%) & \multicolumn{2}{|c|}{$3.1 \pm 2.5$} & \multicolumn{2}{|c|}{$2.9 \pm 2.5$} & 0.9 \\
\hline Immediate post-procedure serum $\mathrm{Na}+\operatorname{drop}(\mathrm{mmol} / \mathrm{L})$ & \multicolumn{2}{|c|}{$2.5 \pm 1.4$} & \multicolumn{2}{|c|}{$2.3 \pm 2.1$} & 0.31 \\
\hline Calculated Blood loss (mL) & \multicolumn{2}{|c|}{$260 \pm 143$} & \multicolumn{2}{|c|}{$91 \pm 35$} & 0.0001 \\
\hline Operation time (min) & \multicolumn{2}{|c|}{$101 \pm 29$} & \multicolumn{2}{|c|}{$117 \pm 24$} & 0.017 \\
\hline Resected volume (gm) & \multicolumn{2}{|c|}{$54 \pm 19$} & \multicolumn{2}{|c|}{$15 \pm 4.7$} & 0.0001 \\
\hline Irrigant fluid volume (L) & \multicolumn{2}{|c|}{$48.8 \pm 13.4$} & \multicolumn{2}{|c|}{$49.5 \pm 11.5$} & 0.44 \\
\hline \multirow[b]{2}{*}{ Intraoperative blood transfusion } & yes & no & yes & no & \multirow[b]{2}{*}{0} \\
\hline & $\begin{array}{c}0 \\
(0 \%)\end{array}$ & $\begin{array}{c}40 \\
(100 \%)\end{array}$ & $\begin{array}{c}0 \\
(0 \%)\end{array}$ & $\begin{array}{c}20 \\
(100 \%)\end{array}$ & \\
\hline
\end{tabular}

The resected prostatic tissue volume was more in B-TURP groups in comparison with the ThuVaRP group, with a significant statistical difference $(54 \pm 19$ and $15 \pm 4.7$ respectively, 0.0001 ).

Regarding blood loss, we found a highly significant statistical difference in favor of the ThuVaRP group,
(Mean \pm SD; $260 \pm 143 \mathrm{ml} / \mathrm{min}$ vs. $91 \pm 35 \mathrm{ml} / \mathrm{min}$ in ThuVaRP and B-TURP groups respectively, $\mathrm{p}=$ 0.0001).

The mean postoperative catheter time $(2.7 \pm 0.5)$ and postoperative hospital stay $(2.5 \pm 0.6)$ was significantly shorter for the ThuVaRP group Table (3).

Table 3. Comparing B-TURP and ThuVaRP group's postoperative course

\begin{tabular}{|c|c|c|c|c|c|}
\hline & \multicolumn{2}{|c|}{ B-TURP } & \multicolumn{2}{|c|}{ ThuVaRP } & P-value \\
\hline Catheter time (days) & \multicolumn{2}{|c|}{$3.3 \pm 0.8$} & \multicolumn{2}{|c|}{$2.7 \pm 0.5$} & 0.001 \\
\hline Hospital stay (days) & \multicolumn{2}{|c|}{$3.2 \pm 0.4$} & \multicolumn{2}{|c|}{$2.5 \pm 0.6$} & 0.0001 \\
\hline \multirow[t]{2}{*}{ Postoperative Hematuria } & yes & no & Yes & No & \multirow{2}{*}{0.8} \\
\hline & $3(7.5 \%)$ & $37(92.5)$ & $1(5 \%)$ & $19(95)$ & \\
\hline \multirow[t]{2}{*}{ Postoperative Blood transfusion } & yes & no & Yes & No & \multirow[b]{2}{*}{0} \\
\hline & $\begin{array}{c}0 \\
(0 \%)\end{array}$ & $\begin{array}{c}40 \\
(100 \%) \\
\end{array}$ & $\begin{array}{c}0 \\
(0 \%) \\
\end{array}$ & $\begin{array}{c}12 \\
(20 \%)\end{array}$ & \\
\hline Postoperative retention & \multicolumn{2}{|c|}{$\begin{array}{c}3 \\
(7.5 \%)\end{array}$} & \multicolumn{2}{|c|}{$\begin{array}{c}2 \\
(10 \%)\end{array}$} & 0.7 \\
\hline 2ry Hematuria after catheter removal & \multicolumn{2}{|c|}{$\begin{array}{c}0 \\
(0 \%)\end{array}$} & \multicolumn{2}{|c|}{$\begin{array}{c}1 \\
(5 \%)\end{array}$} & 0.3 \\
\hline Early irritative LUTS & \multicolumn{2}{|c|}{$\begin{array}{c}24 \\
(60 \%)\end{array}$} & \multicolumn{2}{|c|}{$\begin{array}{c}6 \\
(30 \%)\end{array}$} & 0.0285 \\
\hline Early Postoperative Incontinence & \multicolumn{2}{|c|}{$\begin{array}{c}11 \\
(27.5 \%)\end{array}$} & \multicolumn{2}{|c|}{$\begin{array}{c}3 \\
(15 \%)\end{array}$} & 0.28 \\
\hline TUR syndrome & \multicolumn{2}{|c|}{$\begin{array}{c}0 \\
(0 \%)\end{array}$} & \multicolumn{2}{|c|}{$\begin{array}{c}0 \\
(0 \%)\end{array}$} & 0 \\
\hline
\end{tabular}


Thulium: YAG Laser Vaporesection Versus Bipolar Transurethral Resection of the Prostate for the Treatment of Benign Prostatic Hyperplasia: A Comparative Study

In both groups, there was no need for blood transfusion, neither, intra-operatively nor post-operatively. Also, TUR syndrome did not occur in any patient in our study.

As regard postoperative complications, urine retention and need for re-operation occurred in three cases in the B-TURP group (7.5\%) and two cases in the ThuVaRP group (10\%). But regarding 2ry hematuria was manifested in one patient in the ThuVaRP group (5\%) only that was managed successfully by conservative treatment. As regard postoperative urinary incontinence occurred in eleven cases in the B-TURP group (27.5\%) and three cases in the ThuVaRP group (15\%). All patients were discharged after an uneventful postoperative course and by catheter were removed prior to discharge and successful voiding confirmed.

In our study we have reported a significant improvement in the Qmax, PVR, and IPSS from the baseline for both ThuVaRP and B-TURP groups after 3 months postoperatively, but the differences between the two groups were statistically insignificant, the follow up at 12 months: Qmax, PVR, and IPSS score in the ThuVaRP group was (Mean \pm SD; $16.2 \pm 1.8$, $47.5 \pm 13.7$ and $5.4 \pm 2.8$ respectively) and in the B-TURP (Mean \pm SD was $15.3 \pm 1.2,39.4 \pm 18.7$ and $4.7 \pm 3.1$ respectively) (Table :4).

\section{Discussion}

Currently, there are many acceptable treatmentoptions for patients with BPH, including watchful waiting, medical therapy, minimally invasive treatments, and open prostatectomy ${ }^{8}$. TURP accounted for almost $25 \%$ of all urologic operations and considered as the gold standard treatment for patients with symptomatic $\mathrm{BPH}^{9}$, with excellent short-term and long-term results and a mortality rate decreased dramatically approaching zero within the last decade, but still associated with a significant morbidity ${ }^{10}$.

Modifications such as incorporation of bipolar technology (B-TURP-in saline) have been made to minimize its complications and to increase the volume of the gland that can be safely tackled ${ }^{11}$.

Various new technologies have been developed that aim to minimize the morbidity of TURP ${ }^{12}$. Based over the technology of thulium, green light, and holmium laser; many studies are advocating these substitutes for TURP or open prostatectomy ${ }^{13}$.

According to previous studies, HoLEP enables the endoscopic removal of prostatic adenoma regardless of its size and is as effective as open prostatectomy; moreover, it can decrease the severity of complication ${ }^{14,15}$.

Despite good clinical results, both of PVP and HoLEP procedures have shown to have various limitations. For PVP, no tissue specimen is provided for histological evaluation, and the speed of tissue ablation is significantly slower ${ }^{16}$.

For HoLEP, the steep learning curve and longer operation time seem to be the major drawbacks and limit its widespread clinical application ${ }^{17}$.

The recently developed Thulium: YAG laser with a wavelength of $2013 \mathrm{~nm}$ allowing its easy absorption, and a continuous mode that provides more effective homeostasis. In addition, it provides accurate resection with sufficient vaporization, while moving laser probe maximizes vaporization and reduces the heat applied to tissue ${ }^{18}$.

The drawbacks of other laser procedures seem better avoidable with the thulium laser because the vaporesection technique creates tissue chips small enough to be evacuated, while an additional tissue morcellation is not necessary at the end of the procedure avoiding the risk of bladder injury and allowing retrieval of tissue for histopathology.

At the same time, thulium vaporesection is a userfriendly TURP-like technique requiring less expertise and a shorter learning curve than HoLEP ${ }^{19}$.

Xia et al published their initial clinical report on Thulium: YAG laser prostate surgery. They performed ThuVaRP with the tangerine technique on 50 patients and reported its safety and efficacy ${ }^{20}$.

At 12 months follow-up clinic visits; both groups showed marked improvement in IPSS, Qmax, and PVR.

Limitations: The small size of study candidates and the short follow-up period, which necessitate a validation of the aforementioned results on a larger scale with more extended follow-up period. 
Thulium: YAG Laser Vaporesection Versus Bipolar Transurethral Resection of the Prostate for the Treatment of Benign Prostatic Hyperplasia: A Comparative Study

\section{CoNCLUSION}

ThuVaRP proved to be a safe and effective method for treatment of patients with BPH, with comparable efficacy, shorter hospital stay, and faster recovery compared to B-TURP.

\section{Compliance with Ethical Standards}

Ethical Approval: All procedures performed in studies involving human participants were in accordance with the ethical standards of the institutional and/or national research committee and with the 1964 Helsinki declaration and its later amendments or comparable ethical standards

Informed Consent: Informed consent was obtained from all individual participants included in the study

\section{REFERENCES}

[1] BerrySJ,CoffeyDS,WalshPC,etal.Thedevelopment of human benign prostatic hyperplasia with age. J Urol. 1984 Sep;132(3):474-9.

[2] Hwang, E.C., J.S. Joo, K.D.Min , et al., A shortterm comparative study on efficacy and safety of standard transurethral resection and high power $(80 \mathrm{~W})$ potassium-titanyl-phosphate laser vaporization of the prostate. Korean J Urol, 2005. 46(12): p. 1251-1255.

[3] Madersbacher S, Alivizatos G, de la Rosette JJ, et al. EAU 2004 guidelines on assessment, therapy and follow-up of men with lower urinary tract symptoms suggestive of benign prostatic obstruction (BPH guidelines). Eur Urol. 2004 Nov;46(5):547-54.

[4] Wasson JH, Reda DJ, Henderson WG, et al. A comparison of transurethral surgery with watchful waiting for moderate symptoms of benign prostatic hyperplasia. The Veterans Affairs Cooperative Study Group on Transurethral Resection of the Prostate. N Engl J Med. 1995 Jan 12;332(2):75-9.

[5] Kuntz RM. Current role of lasers in the treatment of benign prostatic hyperplasia (BPH). Eur Urol. 2006 Jun;49(6):961-9. Epub 2006 Mar 31.

[6] Fried NM, Murray KE. High-power thulium fiber laser ablation of urinary tissues at 1.94 microm. J Endourol. 2005 Jan-Feb;19(1):25-31.
[7] Roman Szlauer, Robert Götschl, Szlauer, R., et al., Endoscopic vaporesection of the prostate using the continuous-wave $2-\mu \mathrm{m}$ thulium laser: outcome and demonstration of the surgical technique. Eur Urol., 2009. 55(2): p. 368-375.

[8] Oelke M, Bachmann A, de la Rosette J, et al; European Association of Urology. EAU guidelines on the treatmentand follow-up of non-neurogenic male lower urinary tract symptomsincluding benign prostatic obstruction. Eur Urol. 2013 Jul;64(1):118-40.

[9] Madersbacher S, Lackner J, Willinger M,Schatzl G, et al; Prostate Study Group of the Austrian Society of Urology. Reoperation,myocardial infarction and mortality after transurethral and open prostatectomy: a nation-wide, longterm analysis of 23,123 cases. Eur Urol. 2005 Apr;47(4):499-504.

[10] RoderickMacdonald,ManojMonga,Hoffman,R.M., et al., Transurethral microwave thermotherapy vs transurethral resection for treating benign prostatic hyperplasia: a systematic review. BJU international, 2004. 94(7): p. 1031-1036.

[11] Mamoulakis, C., M. Trompetter, and J. de la Rosette, Bipolar transurethral resection of the prostate: the 'golden standard'reclaims its leading position. Curr opin urol, 2009. 19(1): p. 26-32.

[12] J. Curtis Nickel, Carlos E. Méndez-Probst, Hassan Razvi ,et al. 2010 Update: Guidelines for the management of benign prostatic hyperplasia Can Urol Assoc J. 2010 Oct; 4(5): 310-316.

[13] Bach, T. Piotr Paweł Świniarski, Stanisław Stępień, et al., Thulium: YAG laser enucleation (VapoEnucleation) of the prostate: safety and durability during intermediate-term follow-up. World journal of urology, 2010. 28(1): p. 39-43.

[14] Elzayat, E.A. and M.M. Elhilali, Holmium laser enucleation of the prostate (HoLEP): the endourologic alternative to open prostatectomy. Eur Urol, 2006. 49(1): p. 87-91.

[15] Hwang, J.C., S.M. Park, and J.B. Lee, Holmium laser enucleation of the prostate for benign prostatic hyperplasia: effectiveness, safety, and overcoming the learning curve. Korean $\mathrm{j}$ urol, 2010. 51(9): p. 619-624. 
Thulium: YAG Laser Vaporesection Versus Bipolar Transurethral Resection of the Prostate for the Treatment of Benign Prostatic Hyperplasia: A Comparative Study

[16] Ruszat, R., Gasser TC, Bachmann A. , et al., GreenLight laser vaporization of the prostate: a single-center experience and long-term results after 500 procedures. Eur Urol, 2008. 54(4): p. 893-901.

[17] Elzayat, E.A. and M.M. Elhilali, Holmium laser enucleation of the prostate (HoLEP): long-term results, reoperation rate, and possible impact of the learning curve. Eur Urol, 2007. 52(5): p. 1465-1472.

[18] Bach T, Herrmann TR, Ganzer R, Burchardt M,
Gross AJ. RevoLix vaporesection of the prostate: initial results of 54 patients with a 1-year followup. World J Urol. 2007 Jun;25(3):257-62.

[19] Seitz, M., Editorial comment on thulium laser versus standard transurethral resection of the prostate: a randomized prospective trial. Eur Urol, 2008. 53(2): p. 390.

[20] Xia SJ, Zhuo J, Sun XW, et al. Thulium laser versus standard transurethral resection of the prostate: a randomized prospective trial. Eur Urol. 2008 Feb;53(2):382-89.

Citation: Mohamed Selim, Mohamed Marzouk Abdella, Mohamed Rokba, Alaa el Mahdy, Mohamed Omar. Thulium: YAG Laser Vaporesection Versus Bipolar Transurethral Resection of the Prostate for the Treatment of Benign Prostatic Hyperplasia: A Comparative Study. Archives of Urology. 2018; 1(2): 38-43.

Copyright: (C) 2018 Mohamed Selim, Mohamed Marzouk Abdella, Mohamed Rokba, Alaa el Mahdy, Mohamed Omar. This is an open access article distributed under the Creative Commons Attribution License, which permits unrestricted use, distribution, and reproduction in any medium, provided the original work is properly cited. 